\title{
Limit cycles with transient state dynamics in cyclic networks
}

\author{
Bulcsú Sándor*, Claudius Gros \\ From 24th Annual Computational Neuroscience Meeting: CNS*2015 \\ Prague, Czech Republic. 18-23 July 2015
}

Changes in the transmission properties of synapses may influence actively the processing of information. This is in particular the case for the working memory, viz the temporary storage of information, which is thought to be mediated via short-term or transient synaptic plasticity effects [1]. The standard Tsodyks-Markram model [2] for short-term synaptic plasticity allows, in this context, the statistical investigation of spiking neural networks as well as the mean field analysis of rate encoding neural populations [3].

We implement a slightly modified version of the TsodyksMarkram model for cyclic networks characterized by Mexican-hat type connectivity profiles for the synaptic weights. The system shows a surprisingly rich set of dynamical states, even for rings of only four neurons (or neural populations), such as transient state dynamics [4]. In this case one observes extended plateaus in the time series of the population firing rates, indicating well defined transient states (see left panel of Figure 1).

Going beyond the simple mean-field analysis, we present an in-depth study of the bifurcation diagram, as a function of several bifurcation parameters, such as the strength I of the external current or the integration time $1 / \Gamma$ of the neural activity. Four classes of distinct limit cycles are found (see right panel of Figure 1), in addition to stable fixpoints and saddles. We note, that our results

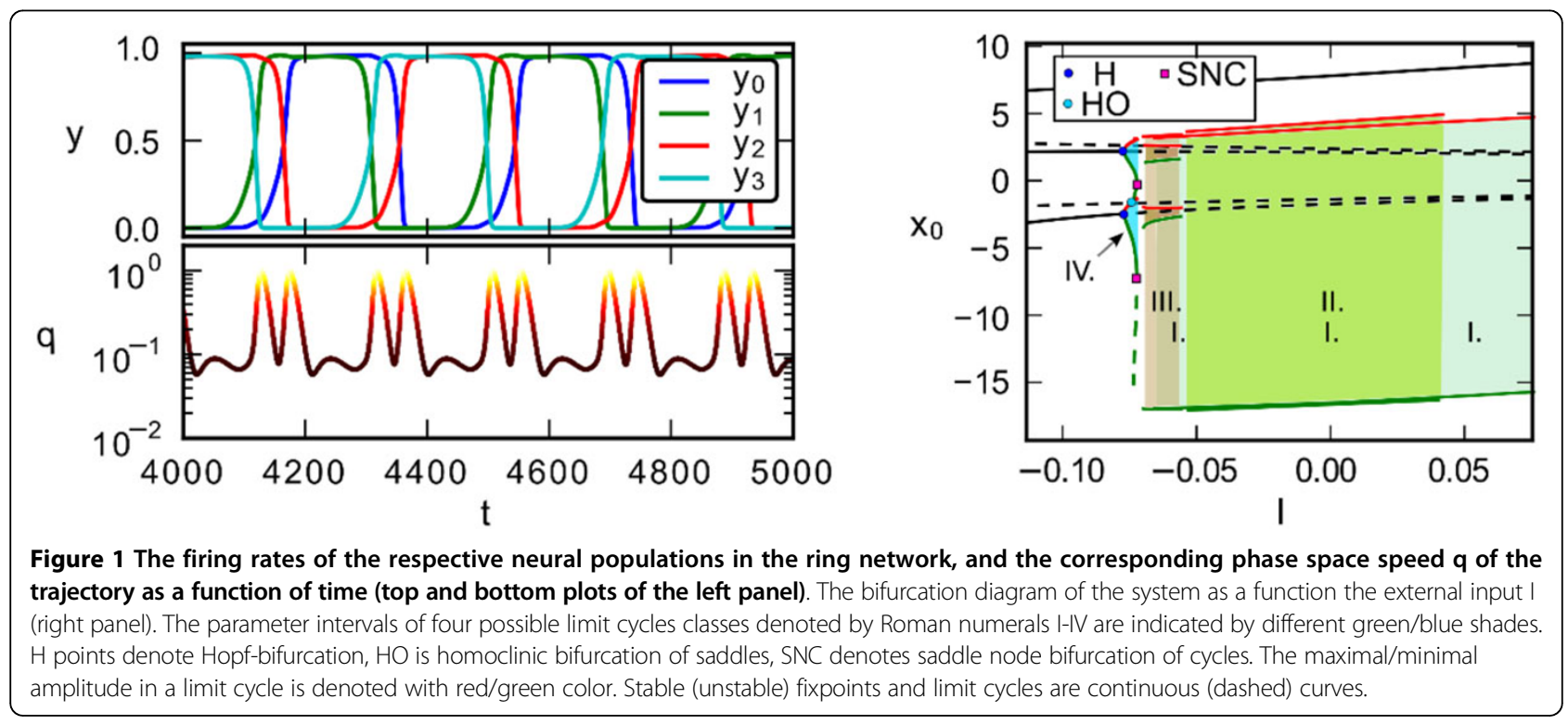

* Correspondence: sandor@itp.uni-frankfurt.de

Institut für Theoretische Physik, Goethe Universität, Frankfurt am Main, 60438, 
are not only important for an in-depth understanding of the network effects of working memory, but also indicate the possibility to construct central pattern generators using short-term synaptic plasticity.

\section{Acknowledgements}

The work of BS was supported by the European Union and the State of Hungary, co-financed by the European Social Fund in the framework of TÁMOP 4.2.4.A/2-11-1-2012-0001 National Excellence Program.

Published: 18 December 2015

\section{References}

1. Mongillo G, Barak O, Tsodyks M: Synaptic theory of working memory. Science 2008, 319(5869):1543-1546.

2. Tsodyks MV, Markram H: The neural code between neocortical pyramidal neurons depends on neurotransmitter release probability. PNAS 1997 , 94(2):719-723.

3. Cortes JM, Desroches M, Rodrigues S, Veltz R, Munoz MA, Sejnowski TJ: Short-term synaptic plasticity in the deterministic Tsodyks-Markram model leads to unpredictable network dynamics. PNAS 2013, 110(41):16610-16615

doi:10.1186/1471-2202-16-S1-P89

Cite this article as: Sándor and Gros: Limit cycles with transient state dynamics in cyclic networks. BMC Neuroscience 2015 16(Suppl 1):P89.

\section{Submit your next manuscript to BioMed Central} and take full advantage of:

- Convenient online submission

- Thorough peer review

- No space constraints or color figure charges

- Immediate publication on acceptance

- Inclusion in PubMed, CAS, Scopus and Google Scholar

- Research which is freely available for redistribution

Submit your manuscript at www.biomedcentral.com/submit 